\title{
Regulation of the hypothalamic-pituitary-ovarian axis in women
}

\author{
Samuel S. C. Yen \\ Department of Reproductive Medicine, School of Medicine, University of California, San Diego, \\ La Jolla, California 92093, U.S.A.
}

\begin{abstract}
Summary. To account for the regulation of cyclic gonadotrophin release, the separate and interactive effects of the hormonal variable at the levels of CNS-hypothalamus, the pituitary and the ovary have been reviewed. The pituitary gonadotrophs, as target cells, exhibited a remarkable cyclic change in their capacity which was correlated with the oestradiol levels. The ultimate release is determined by the relative size of the two pools' releasable gonadotrophins which are themselves regulated by the relative inputs of LH-RH and oestradiol, respectively. LH-RH appears to serve as a primary influence on the gonadotroph, stimulating gonadotrophin synthesis, storage and release. Oestradiol, for the most part, amplifies the action of LH-RH and induces the development of a self-priming effect of LH-RH, except that it impedes LH-RHmediated gonadotrophin release. The pituitary capacity increases several-fold from the early to late follicular phase, and this is considered to be the prerequisite for the development of a mid-cycle surge. CNS-hypothalamic dopamine, norepinephrine, prostaglandins as well as LH-RH systems are involved in the negative and positive feedback effect of oestradiol. The possible steps and interactive elements in the triggering of LH-RH release for the initiation of the mid-cycle LH/FSH surge are considered.
\end{abstract}

In appreciation of our recently acquired knowledge of the neuroendocrine control of cyclic gonadotrophin secretion in women, at least two pioneer contributions should be recalled: in 1932, Moore \& Price discovered the reciprocal relationship between the secretion of the pituitary gonadotrophic hormones and the hormones of the gonads. This finding provided the concept of pituitary control by 'negative feedback' signals emanating from the target gland. In the same year, Hohlweg \& Junkmann (1932) proposed that sex steroids influence gonadotrophin secretion not only by negative feedback (inhibition) but also by positive (stimulating) feedback and that these effects are mediated through a 'sex centre' in the central nervous system. These early observations and concepts are fundamental to the many subsequent studies on pituitary regulation and to the recent advances made in the understanding of the interplay among the elements of the CNS-pituitary-ovarian system in the regulation of cyclic gonadotrophin secretion in women.

The operating characteristics of the hypothalamic-pituitary-ovarian (H-P-O) axis are complex and the cellular and subcellular mechanism(s) governing interaction of the several components of the system are far from understood. Even so, an understanding of the performance of a system may be achieved by determining the relationship between the output as a function of changing input. Unlike other pituitary and target organ systems, the H-P-O system involves multiple trophic hormones with different biological actions (e.g. FSH and LH) and multiple target hormones having nonlinear feedback functions. It is the purpose of this review to provide a brief account of the operating characteristics of the elements of the $\mathrm{H}-\mathrm{P}-\mathrm{O}$ system and to attempt to assemble these elements into a functionally coherent system for controlling the cyclic release of gonadotrophin.

\section{The ovary}

The endocrine components of the ovary

The ovary, inherently a cyclic organ, is composed of two endocrine structures which are morphologically and functionally related: the follicular complex and the corpus luteum. They have sequential 
but overlapping functional life-spans limited to approximately 14 days. In order to accomplish its function, ovarian regulation of the $\mathrm{H}-\mathrm{P}-\mathrm{O}$ system possesses at least three known biological characteristics: (a) an appropriate sequence of negative and positive feedback actions (Yen, Van den Berg, Tsai \& Siler, 1974), (b) a differential feedback effect on the release of LH and FSH (Tsai \& Yen, 1971), which is operable regardless of whether or not a separate FSH-RH exists, and (c) a local regulatory function, within the ovarian unit itself, on follicular growth and maturation, separable from but interrelated to the gonadotrophin action (Lunenfeld, Kraiem \& Eshkol, 1975).

The follicle is the ovarian compartment in which occurs the dual function of oogenesis and steroidogenesis. The functional interaction between the cellular components of the follicular apparatus, i.e. granulosa, thecal and stromal cells, results in steroid production which serves not only as the feedback signal to the hypothalamus and pituitary but also provides local regulatory functions (Lunenfeld, Kraiem \& Eshkol, 1975). Recent evidence suggests that intraovarian oestrogen, androgen and progesterone serve to modulate the growth and maturation of follicles; gonadotrophinstimulated production of oestrogen causes increased ovarian uptake of FSH and hence accelerated follicular maturation. The rising level of oestrogen during the late follicular phase, when FSH levels are actually decreasing, may offer the explanation for the finding that the follicle, as it matures, becomes more sensitive to gonadotrophin stimulation (Goldenberg, Vaitukaitis \& Ross, 1972). Equally important is the finding that intraovarian androgens function to inhibit follicular maturation (Louvet, Harman, Schreiber \& Ross, 1975) and thereby induce follicular atresia. It is apparent then that, in considering the control of follicular growth, it is necessary to take into account not only the stimulation by FSH and LH, but also the stimulatory and inhibitory effects of intraovarian concentrations of oestrogens and androgens. A suppressive effect of progesterone on the number of cytoplasmic oestrogen receptors in the rat uterus has recently been demonstrated (Hsueh, Peck \& Clark, 1975). If this also proves to be true for the ovary, intraovarian progesterone may be critical as a local control mechanism.

\section{The 'ovarian clock'}

Under a variety of experimental conditions, ovarian oestradiol has been shown to exert a stimulating feedback action on gonadotrophin release in the rat (Krey \& Everett, 1973). The most interesting feature of these observations is that oestrogen-induced surges of LH were observed only in the afternoon of pro-oestrus, suggesting the involvement of a 'CNS clock'. Since the LH surge can be blocked by the administration of antibodies to oestradiol-17 $\beta$ (Ferin, Tempone, Zimmering \& Van de Wiele, 1969), it was proposed that, in the rat, ovarian oestradiol determines the day of the surge while the CNS determines its hour of onset (Bogdanove, 1972).

Recent studies of gonadotrophin secretion have revealed a remarkable similarity between the menstrual cycles in women (Yen, Lasley, Wang, Leblanc \& Siler, 1975) and those in rhesus monkey (Knobil, 1974). The control of menstrual cycles appears to be fundamentally different from the control of oestrous cycles in the rat; the evidence indicates an 'ovarian clock' rather than a 'CNS clock' in the regulation of cyclic gonadotrophin surge in the primate. The evidence supporting the role of ovarian oestradiol as the critical feedback signal in the regulation of cyclic gonadotrophin release has been extensively reviewed for man (Ross et al., 1970; Van de Wiele et al., 1970; Yen et al., 1974) and rhesus monkey (Knobil, 1974).

\section{The pituitary}

The pituitary, as an isolated unit, has little if any function. It is dependent on hypothalamic input and its resulting output is determined by the magnitude of the hypothalamic stimulus and the cyclic feedback control exerted by the ovary.

It is now well established that ovarian oestradiol exerts both negative (Tsai \& Yen, 1971; Yen, \& Tsai, 1971b) and positive (Monroe, Jaffe \& Midgley, 1972; Yen \& Tsai, 1971a; Yen \& Tsai, 1972) feedback effects on both the hypothalamus and the pituitary, but the co-ordination of their operation 
remains enigmatic. Further, the positive feedback effect of oestrogen on gonadotrophin release has been viewed as being paradoxical because, in most circumstances, oestrogen inhibits gonadotrophin secretion. These effects were once considered to be mediated through their feedback action on the central nervous system, but the availability of synthetic LH-RH led to the validation of an early proposal made by Bogdanove (1963) that oestrogen exerts its effect directly on the pituitary (Lasley, Wang \& Yen, 1975; Van den Berg, DeVane \& Yen, 1974; Wang \& Yen, 1975; Yen et al., 1975) as well as on the neuronal elements of the CNS (McEwan, Denef, Gerlach \& Plapinger, 1974; Spies \& Norman, 1975; Stumpf, Sar \& Keeper, 1975).

In our attempt to define the elements of the system of the oestrogen feedback regulation of gonadotrophin release, a relatively simple approach was designed with the basic premise that the level of activity of the gonadotrophs, as a target organ, at any given time is determined by the relative inputs of LH-RH and oestradiol.

When submaximal doses of LH-RH (Rebar et al., 1973) are applied over a period of several hours, either by repeated pulses $(10 \mu \mathrm{g}$ at $2-\mathrm{h}$ intervals) or by constant infusion $(0.2 \mu \mathrm{g} / \mathrm{min})$, the pattern of pituitary response (LH release) suggests that gonadotrophins exist in two distinguishable pools or activities-one immediately releasable and the other requiring continued stimulus. When a near maximal dose of LH-RH $(100-150 \mu \mathrm{g})$ is used, the activity of the two pools cannot be distinguished because the sustained action induces release from the first pool and also part of the second pool (Wang, Lasley \& Yen, 1976a).

These two functional pools of LH are demonstrable in all phases of the menstrual cycle. From the early to the mid-follicular phase, in synchrony with the rising levels of oestradiol, the size of the second pool is preferentially augmented. An enlargement of the first pool is not apparent until the late follicular phase, when a 5-fold increase in the size of the second pool is also attained. This increase in the first pool size at the late follicular phase may be explained by a rapid shifting of LH from the much larger second pool to the more readily releasable first pool but without an increase in basal release. Although the precise mechanism for this phenomenon is not known, data obtained in this laboratory suggests that the development of a self-priming effect of LH-RH at this time (Wang, Lasley, Lein \& Yen, 1976b) is one of its manifestations without necessarily implying an increase in endogenous LH-RH. The self-priming effect of LH-RH is manifested as an augmented gonadotrophin release in response to a second pulse of LH-RH given $2 \mathrm{~h}$ after a first or 'priming' pulse. A similar phenomenon has been observed in the rat (Aiyer, Chiappa \& Fink, 1974). The effect is oestrogen dependent and can be produced in hypogonadal subjects after oestrogen therapy (Lasley et al., 1975). The enlarged first pool may not be apparent without additional LH-RH treatment as imposed in our experimental conditions, and in normal circumstances, therefore, the increase in the first pool may represent a potential only. In subjects with little or no pre-existing ovarian feedback (hypogonadal women) (Yen, Tsai, Van den Berg \& Rebar, 1972) or in normal women during the early follicular phase, we have demonstrated that oestrogen appears (a) to promote or to accelerate the LH-RH-dependent increase in the second gonadotrophin pool, probably through sequential processes of LH synthesis and storage, but (b) to impede LH-RH-mediated LH release (Lasley et al., 1975; Wang et al., 1976b; Yen \& Lein, 1976; Hoff, Lasley, Wang \& Yen, 1977).

The effect of relatively high progesterone as well as oestradiol levels during the mid-luteal phase on the two LH pools is of particular interest. During this phase of the cycle, the large second pool is maintained as in the late follicular phase, but the first pool is very much smaller (Hoff et al., 1977). This phenomenon is probably not due to an inhibitory effect of combined oestradiol and progesterone on LH-RH-mediated gonadotrophin release, but occasioned by the extremely low endogenous release of LH-RH at the mid-luteal period, as postulated previously,(Wang et al., 1976b); this in turn minimizes the self-priming effect of LH-RH and results in a reduction of activity of the first pool. When an adequate or excessive amount of LH-RH stimulation is provided, as in the case of prior priming by a 4-h LH-RH infusion, an extraordinary augmentation of the acutely releasable pool of LH is found which exceeds that observed in both the early and the late follicular phase of the cycle (Hoff et al., 1977). These findings provide strong support for our contention that (1) the mid-luteal levels of oestradiol and progesterone do not inhibit the pituitary response to LH-RH action but may in fact possess the potential to amplify first-pool activity by additional LH-RH. (2) Combined 
oestradiol and progesterone at mid-luteal levels apparently suppress endogenous LH-RH release more than does oestradiol alone. Recent evidence suggests a causal relationship between episodic LH-RH secretion and pulsatile LH release (Carmel, Araki \& Ferin, 1976; Dowd, Barofsky, Chaudhuri, Lloyd \& Weisz, 1975). Thus the low-frequency LH pulses uniquely found during the luteal phase of the cycle (Santen \& Bardin, 1973; Yen, Tsai, Naftolin, Van den Berg \& Ajabor, 1972) and the consequently low LH levels may represent an as yet undefined progesterone action on the neuronal mechanism(s) involved in release of LH-RH.

In contrast to both the follicular and the luteal phase, there is an enormous increase in the firstpool activity at mid-cycle (Hoff et al., 1977), a situation also apparent in acyclic hypogonadal subjects (Moore \& Price, 1932). Although the oestradiol levels are at the two extremes under these two conditions, the common denominator is an elevated hypothalamic LH-RH input to the gonadotrophs (Ben-Jonathan, Mical \& Porter, 1973; Carmel et al., 1976; Porter, Ben-Jonathan, Oliver, Eskay \& Winter, 1976). Under this inffuence, both pools are enlarged but with an unusually rapid expansion of the first pool. This situation can be explained by an increased synthesis and storage (second pool) as well as by a rapid shift from the second to the first pool through the increased hypophysiotrophic effect of LH-RH and its self-priming action. The latter function is present only when oestradiol levels are high and there is a greater increase in the size of the first pool during the mid-cycle than in hypogonadal subjects. LH-RH therefore appears to function in a positive fashion on gonadotrophs, stimulating synthesis-storage, activation and release.

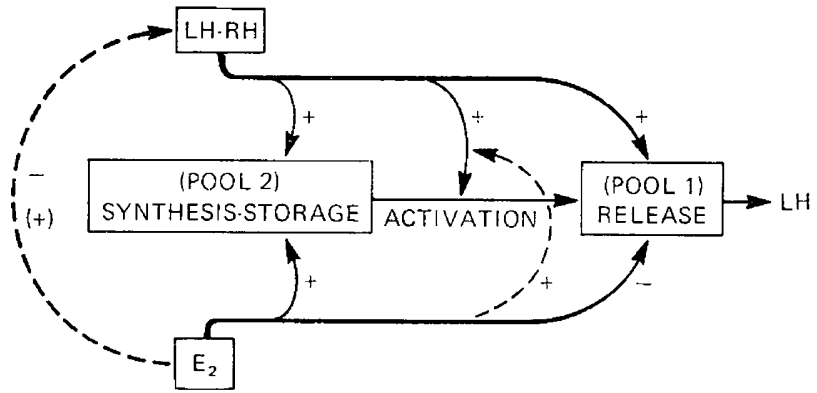

Text-fig. 1. A simplistic representation of the pituitary system involved in LH synthesis-storage, activation and release as related to the two-pool model. The gonadotrophs are the target cells and LH-RH and oestradiol $\left(E_{2}\right)$ are the immediate controllers. LH-RH appears to function in a positive mode on all elements of the system. Oestradiol also appears to provide principally a positive input with two qualifications: (1) the positive effect of oestradiol on Pool 2 depends on the presence of appropriate amounts of LH-RH; (2) there is an impediment effect of oestradiol on the releasing effect of LH-RH. Because the development of the oestrogen-dependent self-priming effect of LH-RH (dashed line) may overcome the impeding action, additional inhibitory factors may be required to stabilize the system. We propose that the tuberoinfundibular dopamine system may play this role. In this diagrammatic presentation, the total capacity of the gonadotrophs is determined by the size of the two pools of gonadotrophin, which are governed by the relative inputs of LH-RH and oestradiol and the development of the oestrogen-dependent self-priming effect of LHRH. The feedback effect of oestradiol on LH-RH release is principally a negative one except at the midcycle surge.

These data give further emphasis to our previous observations which indicate that the dynamic changes in the pituitary gonadotrophs constitute an essential step in the development and initiation of the cyclic gonadotrophin output in women. A functional scheme in the regulation of the two-pool system of LH release during the follicular phase of the cycle is proposed in Text-fig. 1. Operationally, LH-RH not only induces synthesis-storage (Pool 2) and release (Pool 1) but also activates the second pool by converting its $\mathrm{LH}$ to the readily releasable form and, consequently, enlarging the first pool. These positive inputs exerted by LH-RH are amplified by the presence of oestradiol which appears to provide a 'permissive action' of LH-RH on synthesis-storage and activation, possibly by increasing the number of receptors for LH-RH on the gonadotroph. This permissive action of oestradiol appears to be selective, because oestradiol also impedes the LH-RH-mediated LH release. The 
feedback relationship between oestradiol and LH-RH is principally a negative one, except at the time of mid-cycle surge. The system described may not be stable enough to control the relatively low basal secretion during the follicular phase, since the impeding action of oestradiol on $\mathrm{LH}$ release may be overcome by the development of the self-priming effect of $\mathrm{LH}-\mathrm{RH}$. We have therefore speculated that the tuberoinfundibular dopamine system may provide a stabilizing function in the system for $\mathrm{LH}$ release, because we have found that dopamine exerts an inhibitory action on LH (but not FSH) release in man (Leblanc, Lachelin, Abu-Fadil \& Yen, 1976). Work is in progress to determine the role of hypothalamic dopamine in the regulation of gonadotrophin dynamics. At any rate, these dynamic changes of the two pools elicited by supraphysiological levels of stimulus should not be viewed as two physically separated compartments, but functionally they may serve to provide a single integrated process of LH synthesis-storage, activation and release, a process whose activity at any given time is determined by the combined influences of oestradiol, progesterone and LH-RH.

\section{The CNS-hypothalamic component}

The CNS-hypothalamus complex represents the ultimate site of the integrative control. It is endowed with a complex neural network and the biochemical machinery (i.e. biogenic amines and prostaglandins) necessary for the reception, translation and transmission of signals both from within and without the CNS and is subject to feedback control by the ovary.

The prevailing view regarding CNS regulation of gonadotrophin secretion is that diverse neural inputs converge upon the medial basal hypothalamus $(\mathrm{MBH})$ and operate through neurotransmitters which lead to the release of LH-RH by the neurosecretory neurones and subsequent pituitary release of LH and FSH (Wurtman, 1971; Halaz, 1972).

\section{The hypothalamus}

The dramatic changes in pituitary capacity during the menstrual cycle provide a basis for rationalizing the hypothalamic influence on the operating characteristics of the pituitary. During the late follicular and mid-luteal phases of the cycle, when the pituitary capacity is high and the self-priming effects of LH-RH are at a maximum, the relatively low basal gonadotrophin secretion normally found requires that endogenous $\mathrm{LH}-\mathrm{RH}$ release be very low. The modest increase in basal LH secretion observed just before the onset of the mid-cycle surge (Midgley \& Jaffe, 1968; Ross et al., 1970; Yen, Vela, Rankin \& Littell, 1970) may reflect the beginnings of incremental LH-RH secretion; increased amounts of LH-RH have been found at the time of the mid-cycle surge in the portal blood of rhesus monkeys (Carmel et al., 1976) and in peripheral blood of women (Arimura, Kastin \& Schally, 1974; Malacara, Seyler \& Reichlin, 1972). The increased pituitary capacity, the development of the oestrogen-induced self-priming effect of LH-RH and the increments in LH-RH release may represent the combination required to induce the stepwise release of LH at the time of the midcycle surge.

With the significantly lower basal gonadotrophin secretion (Ross et al., 1970) at the time of high pituitary capacity during the mid-luteal phase, endogenous LH-RH should be very low. A progressive decrease in sensitivity and reserve characterizes pituitary function from the mid-luteal to lateluteal phase and into the early follicular phase of an ensuing cycle (Wang et al., 1976b). This is probably largely the result of the progressive decline in concentration of ovarian steroids on which sensitivity and reserve appear to be dependent. However, the elevation in basal LH and FSH release when there is reduced pituitary capacity during the early follicular phase requires postulation of a transient increase in LH-RH release and/or a decrease in the proposed ovarian inhibitory factor (inhibin). A differential action on FSH and LH secretion must be considered to account for the higher level of FSH than LH seen at this time.

\section{The brain as an endocrine organ}

The recent demonstration of specific receptors (Davies, Naftolin, Ryan \& Siu, 1975) or binding sites in the brain as well as in the pituitary for gonadal steroids supports the concept that distinct areas 
of the brain participate in specific neuroendocrine events (McEwan et al., 1974; Stumpf et al., 1975). Further, the brain, particularly the hypothalamus, possesses the capacity for steroid transformation, which may influence CNS differentiation and hypothalamic function (Naftolinet al., 1975). Although their significance remains to be established, four biochemical transformations seem at present to be of major consideration: (a) aromatization of androgens to oestrogens, (b) $5 \alpha$ reduction of testosterone, (c) $5 a$ reduction of progesterone and (d) the formation of catecholoestrogen (Ball, Knuppen, Haupt \& Breuer, 1972; Fishman \& Norton, 1975).

Thus, the brain not only serves as a target for steroid hormones but also possesses the capacity of synthesis de novo and secretion of numerous peptide hormones. The recent detection of these peptides in many discrete regions of the CNS and in nerve terminals has led to postulation of the existence of a system of peptidergic neurones in the brain, analogous to the catecholaminergic systems, with axon terminations on the hypothalamic-pituitary portal system. These peptide hormones may play a significant role in the integration of neuroendocrine functions within the brain in addition to their releasing or inhibiting action on the adenohypophysis (Martin, Renaud \& Brazeau, 1975).

\section{Biogenic amines as mediators}

Ample evidence exists to support the hypothesis that neuronal pathways involving serotonin, dopamine and norepinephrine are involved in regulating the secretion of LH by the pituitary (Kamberi, Mical \& Porter, 1971; Kalra, Kalra, Krulich, Fawcett \& McCann, 1972; Kordon \& Glowinski, 1972; Sawyer, Hilliard, Kanematsu, Scaramuzzi \& Blake, 1974; McCann \& Moss, 1975; Fuxe et al., 1977). The evidence is good that these biogenic amines in the brain regions, particularly the hypothalamus, affect neurones which contain the"releasing and/or inhibiting factors.

In a series of studies, utilizing microspectrofluorometry and antiserum to LH-RH, Fuxe et al. (1977) have demonstrated that dopamine and LH-RH terminals are aggregated in the same area of the lateral external layer of the median eminence (ME). The norepinephrine nerve terminals are mainly found in the subependymal layer and to some extent in the medial external layer which also contains dopaminergic nerve terminals. This morphological evidence for the potential interaction between dopamine, norepinephrine and $\mathrm{LH}-\mathrm{RH}$ nerve terminals at the ME is supported by the fact that dopamine turnover decreases and norepinephrine turnover increases sharply during the afternoon of pro-oestrus in rats. These data support the concept of an inhibitory dopaminergic mechanism and a facilitatory noradrenergic mechanism in the control of LH-RH secretion.

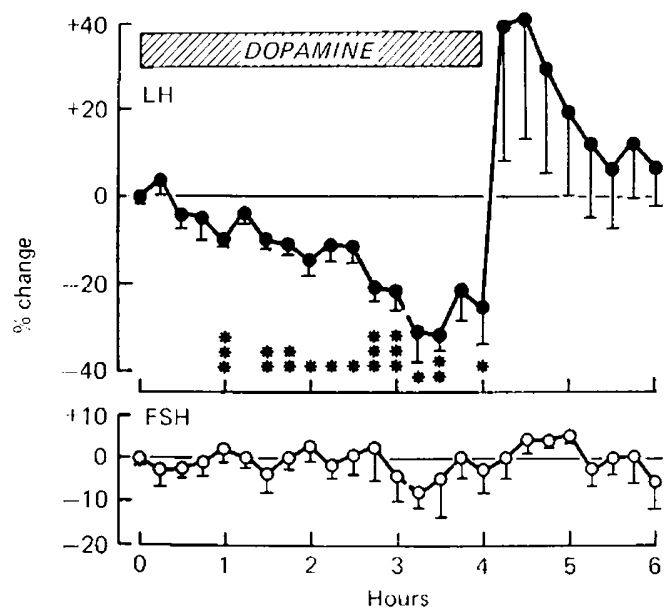

Text-fig. 2. The decline in circulating LH (but not FSH) concentrations during the infusion of dopamine $(4 \mu \mathrm{g} / \mathrm{kg} / \mathrm{min})$ in 4 normal men and 4 normal women during the early follicular phase. An immediate and significant rebound is clearly evident after the discontinuation of the infusion. The data are expressed as the $\%$ change $\left( \pm\right.$ S.E.M.) from mean basal concentration ( 5 determinations at 15 -min intervals). ${ }^{*} P<0.05$, ${ }^{* *} P<0.01,{ }^{* * *} P<0.005$. 
Convincing evidence is now available for a causal relationship between oestrogen and the changes in turnover of catecholamines in the hypothalamus which appears to be dose and time dependent (Fuxe et al., 1977; Kalra et al., 1972); the administration of moderate to high doses of oestradiol benzoate $(1 \cdot 5-60 \mu \mathrm{g})$ to spayed female rats induced a marked and selective acceleration in the dopamine turnover with concomitant lowering of LH and FSH serum levels. An opposite trend occurs in the norepinephrine nerve terminals. These changes can be revealed within $4 \mathrm{~h}$ and become significant after $24 \mathrm{~h}$. When a smaller dose of oestradiol benzoate was used $(0 \cdot 1 \mu \mathrm{g}), \mathrm{LH}$ secretion increased and this was accompanied by an increase in norepinephrine and a reduction of dopamine turnover.

In man, we have recently demonstrated an inhibitory role of dopamine on $\mathrm{LH}$ release; infusion of dopamine at a dose $(4 \mu \mathrm{g} / \mathrm{kg} / \mathrm{min})$ which had no cardiovascular effect induced a highly significant decline in serum LH levels (Text-fig. 2) (Leblanc et al., 1976). The administration of L-dopa (0.5 g, orally), as well as CB-154, elicited a similar but slow decline (Lachelin, Leblanc \& Yen, 1977). In these experimental conditions, a marked rebound in $\mathrm{LH}$ release was observed at the termination of the dopamine infusion and about 7-8 h after L-dopa ingestion. Whether this $\mathrm{LH}$ rebound observed in our studies is due to a norepinephrine effect via the conversion of dopamine or L-dopa to norepinephrine with time is not clear. Nonetheless, the demonstration in human beings for the first time of an inhibitory effect of dopamine on LH release adds critical support to the hypothesis that the inhibitory feedback control of LH-RH secretion by oestrogen is at least partly exerted at the hypothalamic level by activation of hypothalamic dopaminergic neurones. As noted earlier, theinhibitory feedback action of oestrogen is also exerted at the level of pituitary by impeding the releasing action of LH-RH.

\section{Brain prostaglandins as mediators}

It is now established that prostaglandins (PG) of the $\mathrm{E}$ and $\mathrm{F}$ series stimulate the release of LH and FSH by the pituitary (Harms, Ojeda \& McCann, 1973; Batta, Zanisi \& Martini, 1974; Ratner, Wilson, Srivastava \& Peake, 1974). Recent studies indicate that PGE-2 (as well as PGF-2 $\alpha$ ) elicits the release of gonadotrophin in vivo by enhancing the release of endogenous LH-RH rather than by a direct effect on the gonadotrophs (Eskay, Warberg, Mical \& Porter, 1975; Ojeda, Wheaton \& McCann, 1975). Further, Harms et al. (1976) have shown that the PGE-2 probably acts directly on LH-RH neurones, independently of biogenic amines, for the release of LH-RH, since the PGE-2 effects cannot be modified by adrenergic, dopaminergic, serotoninergic or cholinergic blocking agents. Additional evidence that PGs play a mediating role in the neuroendocrine regulation of gonadotrophin secretion is afforded by the fact that (a) ovulation can be blocked in rats by treatment with inhibitors of PG synthesis (Orczyk \& Behrman, 1972), and (b) the release of PGF-2 $\alpha$ from the brain occurs in pulses with a circhoral rhythm, and these pulses are subject to attenuation in the same way as are LH pulses by the infusion of oestradiol-17 $\alpha$ (Roberts \& McCraken, 1975).

\section{The triggers to $L H-R H$ release at mid-cycle}

In the preceding discussion, we have emphasized the dramatic increase in the pituitary capacity and the development of the oestrogen-induced self-priming effect of LH-RH as the necessary prerequisites for the development of the mid-cycle gonadotrophin surge. Although the interacting effects of oestradiol, catecholamines and PGs, as illustrated in Text-fig. 3, may all influence the activity of LH-RH neurones, the mechanism for the initiation (triggering) of hypothalamic LH-RH release and the resulting $\mathrm{LH}$ surge at mid-cycle is unknown. Oestradiol appears to act as an inducer but may not be the final effector. Several attractive and testable hypotheses for the initiation of the LH-RH release may be considered.

We have demonstrated that in man progesterone exerts an amplifying effect on the oestrogenaugmented pituitary gonadotrophs, as evidenced by a marked increase in LH-FSH release in response to LH-RH over and above those found for the oestrogen-primed pituitary alone (Lasley et al., 1975). A direct action of progesterone on the pituitary was therefore proposed. However, the 


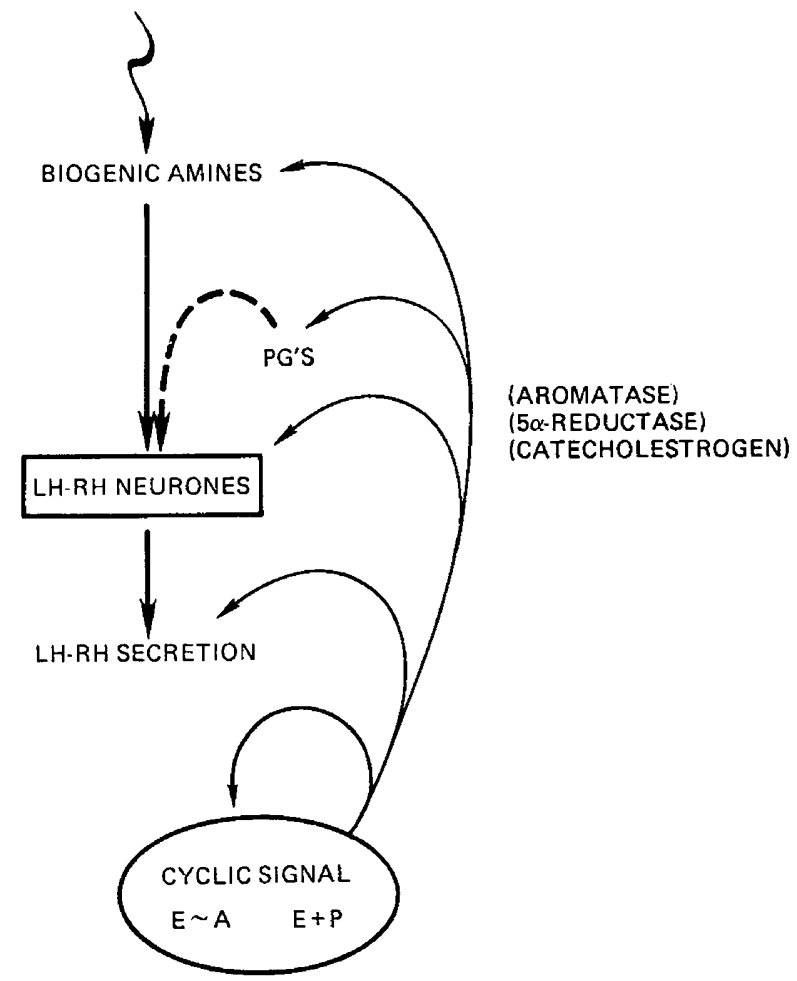

Text-fig. 3. Schematic illustration of the interacting effects of CNS-hypothalamic catecholamines and prostaglandins and their influence by oestradiol (via long-loop feedback) on the regulation of LH-RH neuronal activity. When considering the triggering event of $\mathrm{LH}-\mathrm{RH}$ release, oestradiol is considered as an inducer but not an effector. A short-loop negative feedback between LH-RH secretion and LH-RH neuronal activity may also exist. Participation of ovarian steroids other than oestradiol such as progesterone (P) and androstenedione (A) via conversion within the hypothalamus should be considered. The formation of catecholoestrogen may provide a link between oestrogen and catecholamines for the biochemical steps in the ovarian regulation of $\mathrm{LH}-\mathrm{RH}$ secretion.

administration of an antiserum to LH-RH completely abolished the progesterone-induced acute gonadotrophin surge in ovariectomized rats treated with oestradiol benzoate (Lu \& Yen, 1977). Thus, progesterone appears to exert a facilitatory action on gonadotrophin release through a combined action on the amplification of pituitary sensitivity and on the release of LH-RH as has been implicated previously (Cumming et al., 1972). It has been reasoned that a preovulatory secretion of progesterone by the maturing follicle might represent the final message for the initiation of the mid-cycle surge. However, evidence for a measurable increase in the circulating progesterone before the initiation of the mid-cycle LH surge has not been found.

The interaction between PGs and catecholamines may cause transient vasodilatation (Brody \& Kadowitz, 1974) and, consequently, an increase in LH-RH delivery from the hypothalamus to the pituitary via an increase in blood flow in the hypothalamic-hypophysial portal vessels without an actual increase in neuronal release of LH-RH. An increase in local PG production may stimulate the LH-RH neurone directly to release LH-RH. This may be induced by a reduction of intraneuronal oestrogen concentration brought about by depletion or inhibition of replenishment of cytoplasmic oestrogen-receptor protein, e.g. by increase of the local conversion of 5a-reduced compounds. Since current evidence suggests that norepinephrine stimulates and dopamine inhibits the activity of LH-RH neurones (Fuxe et al., 1977), an increase in their ratio, caused for example by oestrogen at sufficient concentrations, may induce LH-RH release. 
The formation of a catecholoestrogen may serve as a biochemical link between oestrogens and catecholamines in the modulation of neuronal activity (Ball et al., 1972; Fishman et al., 1975). It is speculated that the increased availability of oestradiol and oestrone for binding at the hypothalamic site would facilitate the formation of catecholoestrogen, which in turn, might induce LH-RH release through two possible mechanisms. (i) Catecholoestrogens are effective competitive inhibitors of the degrading enzyme catechol-O-methyl transferase (Ball et al., 1972) and the consequent increase in the norepinephrine effect would facilitate LH-RH release. (ii) Reduction of the negative feedback action of oestradiol on LH-RH neurones via effective competition by catecholoestrogens for the oestrogen receptors (Davies et al., 1975). This postulate requires that catecholoestrogens themselves be devoid of oestrogenic activity which is indeed the case; they may thus function as anti-oestrogens in situ within the hypothalamic LH-RH neurones and thereby promote $\mathrm{LH}-\mathrm{RH}$ release.

Exploration of these interesting possibilities awaits future experiment.

This work was supported by Rockefeller Foundation Grant RF-75029 and National Instit utes of Health Grant HD-09728.

\section{References}

AIYeR, M.S., ChIAPPA, S.A. \& FinK, G. (1974) A priming effect of LH-releasing factor on the anterior pituitary in the female rat. $J$. Endocr. 62, 573-588.

Arimura, A., Kastin, A.J. \& Schally, A.V. (1974) Immunoreactive LH-releasing hormone in plasma: midcycle elevation in women. J. clin. Endocr. Metab. $38,510-513$.

Ball, P., Knuppen, R., Haupt, M. \& Breuer, H. (1972) Interactions between estrogens and catecholamines. J. clin. Endocr. Metab. 34, 736-746.

Batta, S.K., Zanisi, M. \& Martini, L. (1974) Prostaglandins and gonadotropin secretion. Neuroendocrinology 14, 224-232.

Ben-Jonathan, N., Mical, R.S. \& Porter, J.C. (1973) Superfusion of hemipituitaries with portal blood. I. LRF secretion in castrated and diestrous rats. Endocrinology 93, 497-503.

Bogdanove, E.M. (1963) Direct gonadal-pituitary feedback: an analysis of effects of intracranial estrogenic depots on gonadotropin secretion. Endocrinology 72, 696-712.

Bogdanove, E.M. (1972) Hypothalamic-hypophyseal interrelationships: basic aspects. In Reproductive Biology, pp. 5-70. Eds H. Balin \& S. Glasser. Excerpta Medica, Amsterdam.

Brody, M.J. \& Kadowrrz, P.J. (1974) Prostaglandins as modulators of the autonomic nervous system. Fedn Proc. Fedn Am. Socs exp. Biol. 33, 48-60.

Carmel, P.D., Araki, S. \& Ferin, M. (1976) Pituitary stalk portal blood collection in rhesus monkeys: evidence for pulsatile release of gonadotropinreleasing hormone (Gn-RH). Endocrinology 99, 243-248.

Cumming, I.A., Buckmaster, J.M., Cerini, J.C., Cerini, M.E., Chamley, W.A., Findlay, J.K. \& Goding, J.R. (1972) Effect of progesterone on the release of LH induced by a synthetic gonadotropinreleasing factor in the ewe. Neuroendocrinology 10 , 338-348.

Davies, I.J., Naftolin, F., RYan, K.J. \& Siu, J. (1975) A specific high-affinity, limited-capacity estrogen binding component in the cytosol of human fetal pituitary and brain tissue. J. clin. Endocr. Metab. 40, 909-912.

Dowd, A.J., Barofsky, A.-L., ChaudhuRI, N., Lloyd, D.W. \& WeISz, J. (1975) Patterns of LH and FSH release from perfused rat pituitaries in response to infusions of hypothalamic extracts. Endocrinology 96, 243-252.

Eskay, R.L., Warberg, J., Mical, R.S. \& Porter, J.C. (1975) Prostaglandins $\mathrm{E}_{2}$-induced release of LHRH into hypophysial portal blood. Endocrinology 97, 816-824.

Ferin, M., Tempone, A., Zimmering, P.E. \& VAN de WIELE, R.L. (1969) Effect of anti-bodies to $17 \beta-$ estradiol and progesterone on the estrous cycle of the rat. Endocrinology 85, 1070-1078.

Fishman, J. \& NorTon, B. (1975) Catechol estrogen formation in the central nervous system of the rat. Endocrinology 96, 1054-1058.

Fuxe, K., Hökfelt, T., Agnati, L., Löfström, A., EVeritt, B.J., JohansSon, O., JonsSon, G., WuTtKe W. \& GoldsteIN, M. (1977) Role of monoamines in the control of gonadotropin secretion. In Neuroendocrine Regulation of Fertility Karger, Basel (in press).

Goldenberg, R.L., Vairukaitis, J.L. \& Ross, G.T. (1972) Estrogen and follicle stimulating hormone interaction on follicle growth in rats. Endocrinology 90, 1492-1498.

HALAZ, B. (1972) Hypothalamic mechanisms controlling pituitary function. Prog. Brain Res. 38, 97-122.

Harms, P.G., OJeda, S.R. \& McCanN, S.M. (1973) Prostaglandin involvement in hypothalamic control of gonadotropin and prolactin release. Science, N.Y. 181, 760-761.

Harms, P.G., OJeda, S.R. \& McCanN, S.M. (1976) Failure of monoaminergic and cholinergic receptor blockers to prevent prostaglandins $\mathrm{E}_{\mathbf{2}}$-induced luteinizing hormone release. Endocrinology 98, 318-323.

Hoff, J.D., Lasley, B.L., WanG, C.F. \& YeN, S.S.C. (1977) The two pools of pituitary gonadotropin: regulation during the menstrual cycle. $J$. clin. Endocr. Metab. (in press). 
Hohlweg, W. \& Junkmann, K. (1932) Die hormonalnervöse Regulierung der Funktion des Hypophysenvorderlappens. Klin. Wschr. 11, 321-323.

Hsueh, A.J.W., Peck, E.J. \& Clark, J.H. (1975) Progesterone antagonism of the oestrogen receptor and oestrogen induced uterine growth. Nature, Lond. 254, 337-339.

Kalra, P.S., Kalra, S.P., Krulich, L., Fawcett, C.P. \& MCCANN, S.M. (1972) Involvement of norepinephrine in transmission of the stimulatory influence of progesterone on gonadotropin release. Endocrinology 90, 1168-1176.

KAMBeri, I.A., MiCAL, R.S. \& PORTER, J.C. (1971) Hypophysial portal vessel infusion: in vivo demonstration of LRF, FRF and PIF in pituitary stalk plasma. Endocrinology 89, 1042-1046.

KNOBIL, E. (1974) On the control of gonadotropin secretion in the rhesus monkey. Recent Prog. Horm. Res. 30, 1-46.

Kordon, C. \& Glowinski, J. (1972) Role of the hypothalamic monoaminergic neurons in the gonadotropin release-regulating mechanisms. Neuropharmacology 11, 153-162.

KREY, L.C. \& EvereTr, J.W. (1973) Multiple ovarian responses to single estrogen injections early in rat estrous cycles: impaired growth, luteotropic stimulation and advanced ovulation. Endocrinology 93, 377-384.

Lachelin, G.C.L., Leblanc, H. \& Yen, S.S.C. (1977) The inhibitory effect of dopamine agonists on $\mathbf{L H}$ release in women. J. clin. Endocr. Metab. (in press).

Lasley, B.L., Wang, C.F. \& Yen, S.S.C. (1975) The effects of estrogen and progesterone on the functional capacity of the gonadotrophs. J. clin. Endocr. Metab. 41, 820-826.

Leblanc, H., Lachelin, G.C.L., Abu-Fadil, S. \& Yen, S.S.C. (1976) Effects of dopamine infusion on pituitary secretion in humans. J. clin. Endocr. Metab. 43, 668-674.

Louvet, J.-P., Harman, S.M., Schreiber, J.R. \& Ross, G.T. (1975) Evidence for a role of androgens in follicular maturation. Endocrinology 97, 366-372.

LU, K.H. \& YEN, S.S.C. (1977) The involvement of LHreleasing hormone (LHRH) in the progesteroneinduced LH release in estrogen-primed ovariectomized rats. Biol. Reprod. (submitted).

Lunenfeld, B., Kraiem, Z. \& Eshkol, A. (1975) The function of the growing follicle. J. Reprod. Fert. 45, $567-574$.

Malacara, J.M, Seyler, L.E., Jr \& Reichlin, S. (1972) Luteinizing hormone releasing factor activity in peripheral blood from women during the midcycle luteinizing hormone ovulatory surge. J. clin. Endocr. Metab. 34, 271-278.

Martin, J.B., Renaud, L.P. \& Brazeau, P., (1975) Hypothalamic peptides: new evidence for peptidergic pathways in the CNS. Lancet ii, 393-398.

McCanN, S.M. \& Moss, R.L. (1975) Putative neurotransmitters involved in discharging gonadotropinreleasing neurohormones and the action of $\mathrm{LH}$ releasing hormones on the CNS. Life Sciences 16, 833-841.

McEwan, B.S., Denef, C.J., Gerlach, J.L. \& PlapINGER, L. (1974) Chemical studies of the brain as a steroid hormone target tissue. In The Neurosciences, 3rd Study Program, pp. 599-600. Eds X. Schmitt \& Y. Worden. MIT Press, Cambridge, Massachusetts.

Midgley, A.R., JR \& JAFFe, R.B. (1968) Regulation of human gonadotropins. IV. Correlation of serum concentrations of follicle stimulating and luteinizing hormones during the menstrual cycle. J. clin. Endocr. Metab. 28, 1699-1703.

MonRoe, S.E., JAfFe R.B. \& Midgley, A.R., JR (1972) Regulation of human gonadotropin. XII. Increase in serum gonadotropin in response to estradiol. J. clin. Endocr. Metab. 34, 342-347.

MOORE, C.R. \& PRICE, D. (1932) Gonad hormone functions and the reciprocal influence between gonads and hypophysis with its bearing on the problem of sex hormone antagonism. Am. J. Anat. 50, 13-71

Naftolin, F., Ryan, K.J., Davies, I.J., Reddy, V.V., Flores, F. Petro, Z., Kuhn, M., White, R.J., TAKAOKA, T. \& WALIN, L. (1975) The formation of estrogens by central neuroendocrine tissues. Recent Prog. Horm. Res. 31, 295-319.

OJeda, S.R., Wheaton, J.W. \& MCCANN, S.M. (1975) Prostaglandin $\mathrm{E}_{2}$-induced release of luteinizing hormone-releasing factor (LRF). Neuroendocrinology 17, 283-287.

OrczyK, G.P. \& Behrman, H.R. (1972) Ovulation blockade by aspirin or indomethacin; in vivo evidence for a role of prostaglandins in gonadotropin secretion. Prostaglandins 1, 3-6.

Porter, J.C., Ben-Jonathan, N., Oliver, C., Eskay, R.L. \& WINTER, A.J. (1976) Interrelationship of CSF, hypophysial portal vessel, and hypothalamus and their role in the regulation of anterior pituitary gland. In Neuroendocrine Regulation of Fertility, pp. 71-79. Ed. T. C. Anand Kumar. Karger, Basel.

Ratner, A., Wilson, M.C., Srivastava, L. \& Peake, G.T. (1974) Stimulating effects of prostaglandin $E_{1}$ on rat anterior pituitary cyclic AMP and luteinizing hormone release. Prostaglandins 5, 165-171.

Rebar, R., YeN, S.S.C., VANDENBerG, G., NAFtolin, F., Ehara, Y., Engblom, S., Ryan, K.J., Rivier, J., Amoss, M. \& Guillemin, R. (1973) Gonadotropin responses to synthetic LRF: dose-response relationship in men. $J$. clin. Endocr. Metab. 36, 10-16.

Roberts, J.S. \& MCCRACKen, J.A. (1975) Prostaglandin $F 2 \alpha$ production by the brain during estrogeninduced secretion of luteinizing hormone. Science, N. Y. 190, 894-896.

Ross, G.T., Cargille, C.M., Lipsetr, M.B., Rayford, P.L., Marshall, J.R., Strott, C.A. \& Rodbard, D. (1970) Pituitary and gonadal hormones in women during spontaneous and induced ovulatory cycles. Recent Prog. Horm. Res. 26, 1-26.

SANTEN, R.J. \& BARDIN, C.W. (1973) Episodic luteinizing hormone secretion in man. Pulse analysis, clinical interpretation, physiologic mechanisms. $J$. clin. Invest. 52, 2617-2628.

Sawyer, C.H., Hilliard, J., Kanematsu, S., ScaraMUzzI, R. \& BlaKe, C.A. (1974) Effects of intraventricular infusions of norepinephrine and dopamine on LH release and ovulation in the rabbit. Neuroendocrinology 15, 328-337.

SPIES, H.G. \& NoRmaN, R.L. (1975) Interaction of estradiol and LHRH on LH release in rhesus 
monkey: evidence for a neural site of action. Endocrinology 97, 685-692.

Stumpr, W.E., SAR, M. \& KeEPER, D.A. (1975) Anatomical distribution of estrogen in the CNS of mouse, rat, tree shrew and squirrel monkey. $A d v$. Biosci. 15, 77-87.

TSAI, C.C. \& YeN, S.S.C. (1971) Acute effects of intravenous infusion of $17 \beta$-estradiol on gonadotropin release in pre and postmenopausal women. $J$. clin. Endocr. Metab. 32, 766-771.

VAN DEN BerG, G., DeVANe, G. \& YeN, S.S.C. (1974) Effects of exogenous estrogen and progestin on pituitary responsiveness to synthetic luteinizing hormone-releasing factor. $J$. clin. Invest. 53, 17501754.

VAN de Wiele, R.L., Bogumi, J. Dyrenfurth, I., FERIN, M., JeWelewicz, R., WARREN, M., RiXKALlaH, T. \& Mikhail, G. (1970) Mechanisms regulating the menstrual cycle in women. Recent Prog. Horm. Res. 26, 63-104.

WANG, C.F. \& YEN, S.S.C. (1975) Direct evidence of estrogen modulation of pituitary sensitivity to luteinizing hormone releasing factor during the menstrual cycle. J. clin. Invest. 55, 201-204.

WANG, C.F., LAsleY, B.L. \& YeN, S.S.C. (1976a) Gonadotropin secretion in response to low and high doses of LRF in normal and hypogonadal women (functional disparity of the gonadotrophs). $J$. clin. Endocr. Metab. 42, 427-431.

Wang, C.F., Lasley, B.L., Lein, A. \& Yen, S.S.C. (1976b) The functional changes of the pituitary gonadotrophs during the menstrual cycle. J. clin. Endocr. Metab. 42, 718-728.

Wurtman, R.J. (1971) Brain monoamines and endocrine function. Neurosci. Res. Program Bull. 9, 171297.
YEN, S.S.C. \& LEIN, A. (1976) The apparent paradox of the negative and positive feedback control system on gonadotropin secretion. Am. J. Obstet. Gynec. 126, 942-954.

YEN, S.S.C. \& TSAI, C.C. (1971a) The biphasic pattern in the feedback action of ethinyl estradiol on the release of pituitary FSH and LH. J. clin. Endocr. Metab. 33, 882-887.

YEN, S.S.C. \& TSAI, C.C. (1971b) The effect of ovariectomy on gonadotropin release. $J$. clin. Invest. 50 1149-1153.

YEN, S.S.C. \& TSAI, C.C. (1972) Acute gonadotropin release induced by exogenous estradiol during the mid-follicular phase of the menstrual cycle. J. clin. Endocr. Metab. 34, 298-305.

Yen, S.S.C., Vela, P., Rankin, J. \& Littell, A.S. (1970) Hormonal relationships during the menstrual cycle. J. Am. Med. Ass. 211, 1513-1517.

Yen, S.S.C., TSAI, C.C., NAFTOLIN, F., VAN DEN Berg, G. \& AJABOR, L. (1972) Pulsatile patterns of gonadotropin release in subjects with and without ovarian function. J. clin. Endocr. Metab. 34, 671-675.

YeN, S.S.C., Tsai, C.C., VAN DEN BeRG, F. \& REbar, R. (1972) Gonadotropin dynamics in patients with gonadal dysgenesis : a model for the study of gonadotropin regulation. J. clin. Endocr. Metab. 35, 897-904.

YeN, S.S.C., VAN DEN Berg, G., TSAI, C.C. \& Siler, T. (1974) Causal relationship between the hormonal variables in the menstrual cycle. In Biorhythms and Human Reproduction, Ch. 14, pp. 219-238. Wiley, New York.

YeN, S.S.C., LASLeY, B.L., WANG, C.F., Leblanc, H. \& Siler, T.M. (1975) The operating characteristics of the hypothalamic-pituitary system during the menstrual cycle and observations of biological action of somatostatin. Recent. Prog. Horm. Res. 31, 321363. 